\title{
Correction to: A Systematic Literature Review of Usability Evaluation Guidelines on Mobile Educational Games for Primary School Students
}

Xiao Wen Lin Gao, Braulio Murillo, and Freddy Paz

\section{Correction to:}

Chapter "A Systematic Literature Review of Usability Evaluation Guidelines on Mobile Educational Games

for Primary School Students" in: A. Marcus and W. Wang (Eds.): Design, User Experience, and Usability, LNCS 11586, https://doi.org/10.1007/978-3-030-23535-2_13

The book was inadvertently published with an incorrect version of an author's name in Chapter 13. It has been corrected as "Braulio Murillo" in the corresponding chapter. 